\title{
Integration of Computer Aided Design and Manufacturing at Second Year level in Undergraduate Program
}

\author{
Christopher Laing \\ Instructor, Design Engineering \\ University of Manitoba \\ laingc@cc.umanitoba.ca
}

\author{
Subramaniam Balakrishnan \\ Professor, Mechanical \&Manufacturing \\ Engineering \\ University of Manitoba \\ balakri@cc.umanitoba.ca
}

\begin{abstract}
Computer Graphics for Mechanical and Manufacturing Engineering at the University of Manitoba has evolved from a generic first year program to a second year design course that simulates real world experience through the development of a team based project. This challenging and comprehensive program integrates two separate course into one, CAD (Computer Aided Design) and Computer Aided Manufacturing (CAM) Concepts. The latter provides a framework to the process of computer-controlled manufacturing with an emphasis on use of advanced computerized machines. The CAD portion is taught in three stages; the first stage builds proficiency in $3 D$ modeling techniques to create working virtual models. The second stage focuses on the language and communication of mechanical design, and the third stage develops practical skills on a host of modern technology, including CNC (Computer Numerical Control) and rapid prototyping equipment. The second part provides a series of lectures establishing the link between CAD and CAM and culminates in a design project that links the two modules. These complementary programs work hand in hand to provide the necessary theory and practical skill for the students to work in teams, to develop and conclude the term with a working device that they designed, fabricated and tested in one of the two production laboratories allocated to this course. At the conclusion of this program, each device is authenticated to ensure that it has met the criterion which validates both the design as well as the student's learning experience. This paper will endeavour to be candid in sharing our experiences with you. We will cover everything from looking at the history behind this program, to the challenges we met. Most notably, the number of students compared to the
\end{abstract}

equipment available in both the learning and production stages of this course. We will also explore the principals and thinking that constituted the curriculum with the goal that each facet of learning, both in its theory and application directly relates to real world practice that would contribute to the student's field of study and their preparation for industry.

\section{Introduction}

A widespread objective with educators is to provide a quality program that is both meaningful and deliver relevant content. In engineering, one way this has been addressed is by bringing real life practices into the classroom. An example of this is having the students interact with individuals directly from industry known as EIR's (Engineers in Residence). These professionals can share their insight with the variety of applicable learning activities that the students typically go through and relate it to how it is being done in an industrial setting. Another way is by developing projects that have the same content and methods the students would experience if they were practicing engineers. The James Leake, Jacob Borgerson's book, Engineering Design Graphics, states "engineering design can be defined as a set of decision-making processes and activities that are used to determine the form of a product" [1]. More precisely, it is using the theory and science of engineering, and applying it to the design process. This includes problem solving, analytical skills, communication, and collaboration. Having programs like this, not only meets the requirements that industry has been asking for, but also allows our students to be prepared with the necessary skills to disseminate the practice of engineering design that will carry them into industry. 
The MECH-2012, Computer Graphics for Mechanical and Manufacturing Engineering, four-credit hour course has delivered a curriculum that includes, learning the practical tools of $\mathrm{CAD}$, to conceptualize, devise, and manufacture a real-world part. This has been coupled together with manufacturing concepts and processes that teach the method and theory related to current practices in industry, including key concepts specific to the student's term project. In addition, the success of the program is reliant on the students being able to draw from their first year "Engineering Design"-ENG-1430 course, which includes proficiency in creating reports, being practiced in the design process, as well as ability to work in teams.

Shawna Lockhart and Cindy M. Johnson's book, Engineering Design Communication, state "Engineers use graphics in design in three basic ways: to visualize the design idea, to communicate the idea so that others can evaluate it, and to document the design so the product or process can be reliably reproduced and maintained" [2]. The focus of the CAD graphics course has always been relating the work to real-world practices. What has changed with this latest version is the inclusion of more mechanical design. The device each team produces is uniquely theirs. This has been taken from a research stage to a functioning device that they fabricated and tested. The CAD half of the course provided the tools to make this happen.

\section{How this course has evolved}

Just over ten years ago the first course namely Computer Graphics (Course\#130.140) a two credit hour course was started as part of the first year designengineering program. In this preliminary year, the students had not committed to any particular department; therefore, these first year courses were core skills that were universal in their approach to the engineering process.

The CAD course was project-based where the focus of each competency was on what was being created rather than the software itself. The fundamental nature of the course was the communication of design intent. This was done by producing technical drawings and commercial artwork. One notable aspect of this course is that each year for the final project, the students would create and hand over a working drawing package to senior high school machinists who in turn used the drawings to produce the product. The aim of the course was to build competency in both the standards of technical drawing, and using the software to experience its capabilities of communicating design intent.

Between the years 2006 to 2007, the 130.140 course was phased out and replaced with second year Engineering CAD Technology Courses for Civil, Biosystems, and Mechanical engineering students. This was a positive step and a great advantage for both the students and professors. The students were now learning skills specific to their discipline, and the professors had a new skill-set to serve as a learning activity that complemented their individual programs. This was also the first phase of our current Computer Graphics for Mechanical Engineers course that was given the designation of MECH-2010. This was a two-credit stand-alone CAD course.

\section{The current course - the CAD half}

In the year 2009, the Department of Mechanical and Manufacturing Engineering started the first of our current MECH-2012 four-credit courses, with the title, Computer Graphics for Mechanical and Manufacturing Engineering. This was the first time we put two complementary disciplines into a single course. The rationale behind this was to add a design component that was consistent with the requirements of the CEAB (Canadian Engineering Accreditation Board). Which states "Design: an ability to design solutions for complex, open-ended engineering problems and to design systems, components or processes that meet specified needs with appropriate attention to health and safety risks, applicable standards, and economic, environmental, cultural and societal considerations" [3]. The plan was to have the students learn two concurrent streams, the concepts of manufacturing, and the CAD skills to communicate design. Throughout the course, the students would develop their CAD skills on an individual basis, and apply solid modeling techniques to produce parts that were used to create an array of components, including assemblies, parametric drawings, high end artwork, animations, simulations to test designs, and manufacturing of physical models using equipment such as a 3D printer, laser cutter, and CNC (Computer Numerical Control) machines. The following are some examples of the type of skill building the student were learning.

To learn how to go from concept, the students were tasked to design a nut to go on the end of an existing screwdriver body. After they created their unique design, they made an assembly and tested the fit virtually. Then they made a rapid prototyped the 
model and tested the physical model, and as part of their portfolio they created a commercial poster of their design as shown in Figure 1.

To learn how to communicate drawings to a shopfloor personal, they created a set working drawings for a mini-vise made to industry standards that included an exploded view complete with a BOM (Bill of Materials), and one drawing for each component. The criterion for this assignment was a machinist, could build the device from those drawings. The part designed is shown Figure 2. They learned how to create an animation showing how the device moves, how to change colors to highlight components, and use transparency to show internal features. A sample is shown in Figure 3.

\section{DeTOOL NUT D205K15}

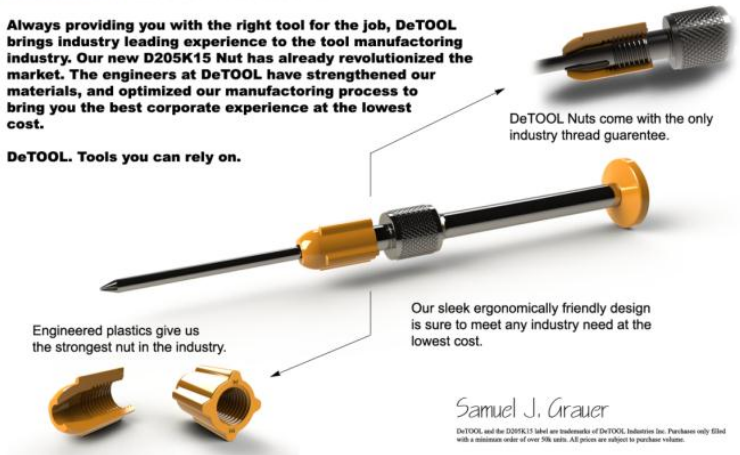

Figure 1-Commercial Poster of the first product

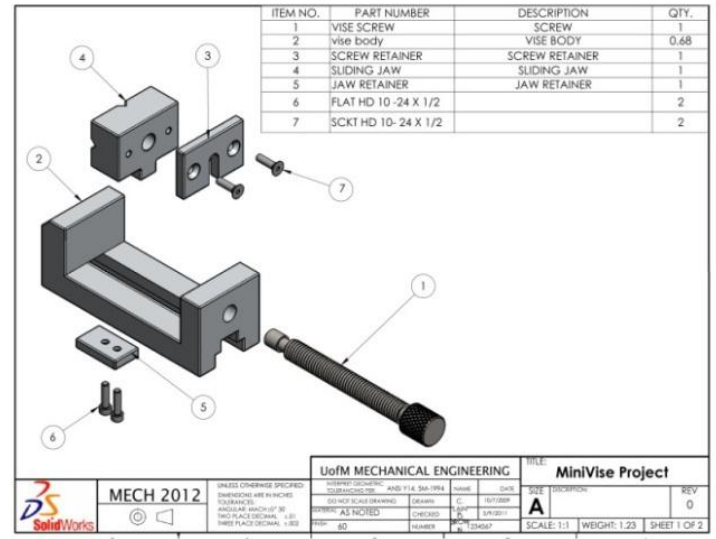

Figure 2-Working drawing for a mini-vise

As an incentive, the students are provided with an opportunity to create a solid-model of a name tag using the CAD software they have become quite familiar with and machine the part using CAM (computer Aided Manufacturing) software. The students are taught to set-up tools, create tool paths and generate code.

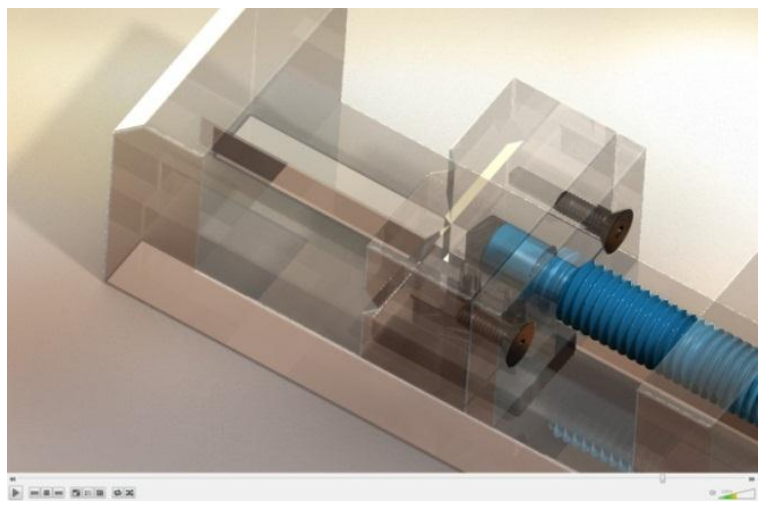

Figure 3-Animation of mini-vise assembly

This code was then posted to our CNC machine where each student machined their personalized name tag shown in Figure 4. With the addition of a chain and clasp, they were able to keep this as a memento.

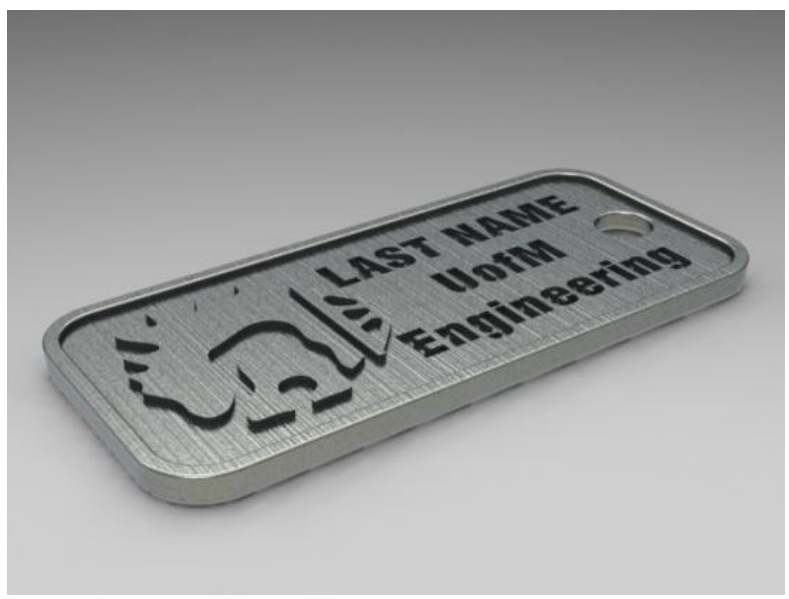

Figure 4-Name tag

\section{Integration of Design and Manufacturing}

The activities mentioned above are typically run during three hours of laboratory time per week allocated to this course. Starting from week one of the course, the students also attend three hours of lecture per week for the entire academic term. The second author of this paper is in-charge of this segment. During week 1 and 2, the students are required to collect material related to all aspects of various types of pumps. This sets the theme for the design they will embark upon in subsequent weeks. The students are required to write a comprehensive report on their findings. The report requirements are very similar to 
that of a literature search for a typical thesis. After the students hand in their report at the end of week 2 of the course, the details of the design problem are presented in the lecture hours. The project for this year is the design, creation of shop drawings, animation in $\mathrm{CAD}$, product development, and testing of a positive displacement pump, specifically a piston type. The students are assigned to groups, typically five in each. The groups are formed by the instructors. The students were given the following constraints. The pump must deliver a minimum of 5Liters/min and must not exceed a flow rate of 10Liters/min. The pump will be driven by a cordless drill whose maximum speed is 600revolutions/minute. Material cost cannot exceed $\$ 50$. The pump developed must be tested on an experimental cell provided with an inlet and outlet tubing, an inlet tank and an outlet chamber. The outlet tube has a flow valve. One of the design requirements is that the pump must produce a minimum of $5 \mathrm{psi}$ of pressure when the shut-off valve is fully closed. The experimental rig is shown in Figure 5. In addition, the students are also given a list of materials that are available for use as building material. A sample of materials is shown in Figure 6.

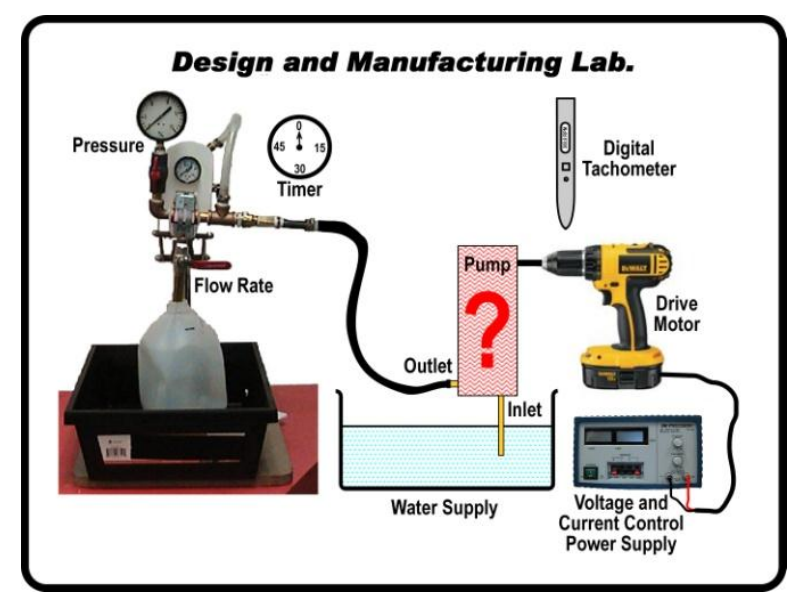

Figure 5 -Experimental setup

It should be noted that students have not completed all of the fundamental mechanical engineering courses at this stage and hence a couple of lectures are devoted to providing them with the basic analysis required to proceed with the design. The students are given two weeks to brainstorm and submit a report outlining the design which includes detailed analysis and calculations establishing design parameters, approximate dimensions of key components, the inlet and outlet valve design, bore size, stroke length and any other pertinent dimensions. In the subsequent week each group goes over the design with the professor and modifications to the design are discussed. In the remaining weeks, the students produce detailed drawings of various components in the CAD software and verify the functionality of their design using animation capabilities of the software. In parallel they also identify the type of machines on which the various components of the pump can be built. This is followed by generation of appropriate control program codes for manufacturing the parts.

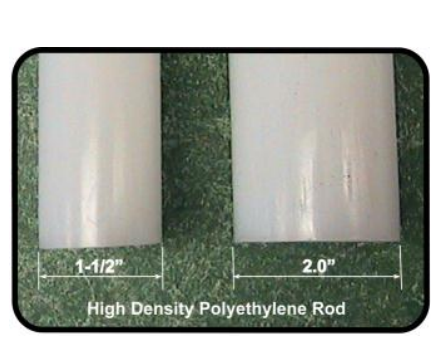

High-density polyethylene rods -1 ", 1 1 $1 / 2$ " and 2" diameter . Recommended material for cylinder.

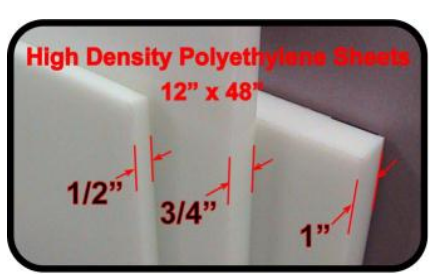

High-density polyethylene sheets $-1 / 2 ", 3 / 4$, 1 ", $1 \frac{1}{2}$ " and $2 "$ thick.

Recommended materials for fabricating various components of the pump.

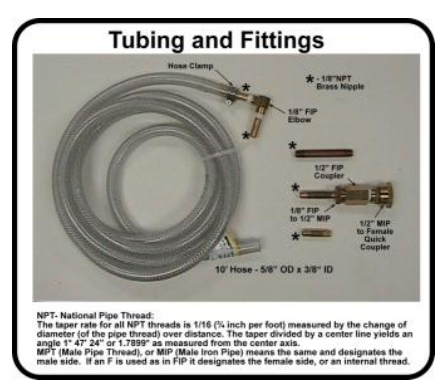

Pre-made tubes and fittings. The design can only incorporate these fittings to normalize testing.

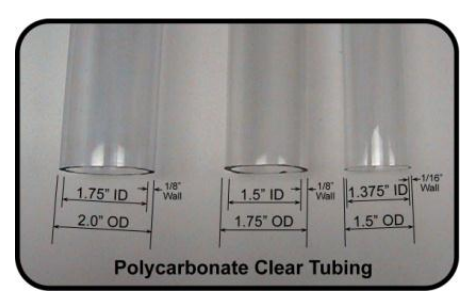

Polycarbonate clear tubing of various sizesrecommended materials for pump cylinder.

Figure 6-Sample of materials 
The CAD drawings are fully utilized for creation of control program codes. This year the parts were produced using a $\mathrm{CNC}$ lathe, a $\mathrm{CNC}$ mill, rapid prototyping machines, and computerized laser cutter. After all the parts are manufactured, the students assemble the pump prior to testing using the setup shown in Figure 5.

This year there were 104 students enrolled in the course and they were divided into 24 groups. Each group was allowed to book times outside the regular class room hours to manufacture the parts. With the number of machines being limited, this was the only way we could manage to provide equal opportunity to all the groups for machining the various parts of the pump. The course had one dedicated technician and five teaching assistants. When all the design and testing is completed, the students are required to write a comprehensive report. Only one submission per group is required. The total mark assigned to the design project was $50 \%$ of the course mark. The remaining marks were allocated to term work and final examination. The students are also required to complete a confidential peer evaluation.

The project also required a final report, a drawing package of their design, an animation showing how the device functions, and a commercial poster to promote their product. It was our intent to make the students present their project before a panel of judges. However this could not be accomplished as we ran out of time.

Of the 23 pumps developed, none were identical. The pumps differed in many ways. Different designs incorporated a wide variety of transferring power from the cordless drill to reciprocating motion of the piston in the cylinder. The sizes of the piston, cylinder and stroke length also differed in every design. The pumps could be classified into several broad categories: single acting, double acting, flywheel based design, cam driven, and multiple piston reciprocating type. Some of the pumps from the current year are shown in Figure 7a-c.

The testing process also required recording flow rate at the design speed, current and voltage consumption by the motor, how was the operation of the pump, pressure measurements and qualitative analysis of leaks through seals. The final report required an introductory section, review of pumps, design proposed and supporting analysis, experimental verification and test results, cost analysis and critical review of the design. The report also included detailed drawings and electronic submission of the animation files.

\section{Results and Challenges}

Of the twenty three designs put forward, twenty two met the pressure requirements. Only five met the flow requirements. Many hidden problems surfaced up. Notable are: too much friction in the drive drain as well as friction between the seal in the piston and the cylinder; leaks in the seals between the cylinder and piston causing reduction in output and pressure losses. The inlet or outlet valves were also cause of problem for some. The increased friction in the system also caused some pumps not being able to operate at the designed speed. The students were required to observe and critically review and comment on the performance of the pump in the final report.

The number of students enrolled in the course was quite large and although the course ended quite successfully and the feedback from students has been quite positive, it did put enormous pressure on the faculty members. The motivation and passion to learn evident in majority of students allowed us to complete the course on time. It was a quite a challenge to mount a course of this nature within a single term. The resources were stretched to the limit. Ideally we need more number of machines and additional resources to accommodate twenty three groups in a period of thirteen weeks. The actual time during which all of the machining, assembly and testing was conducted was six weeks. The course had a formal peer evaluation in place. However the present method of peer evaluation must be improved.

\section{Conclusion, where we go from here}

There are still logistical challenges to be tackled. With a total number of hundred and twenty students in the course, it would be beneficial to extend the course to two terms. This may also change the number of credit hours rising to five from the current 4 credit hours allocated to this course. The CAD portion would be in the first term complementing the skills and concepts required in second term. The curriculum will be much the same, but with important addition of more time for the students to absorb what's being taught. As this course continues to evolve it will endeavour to provide a quality program that is both meaningful and deliver relevant content. We would want our students to get the best and students have shown great enthusiasm in accepting the challenge provided by this course. We will undoubtedly continue to develop our courses following the wisdom of Benjamin Franklin who said, "You tell me, and I forget. You teach me, and I remember. You involve me, and I learn". 


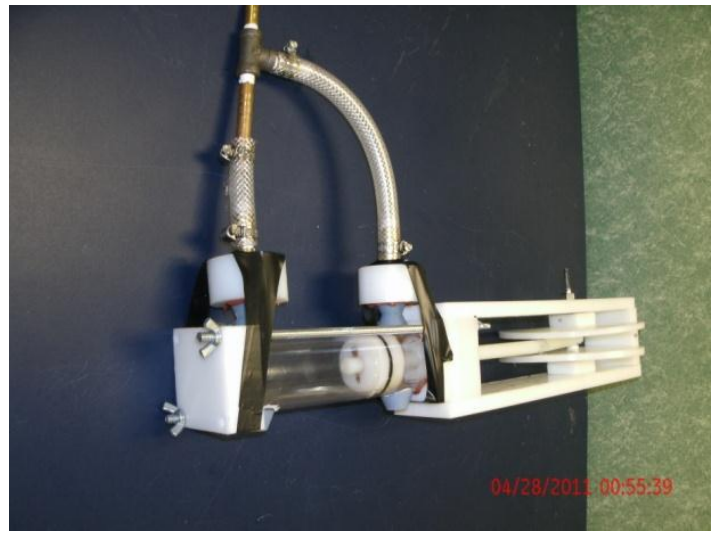

Figure 7a-Double acting piston pump

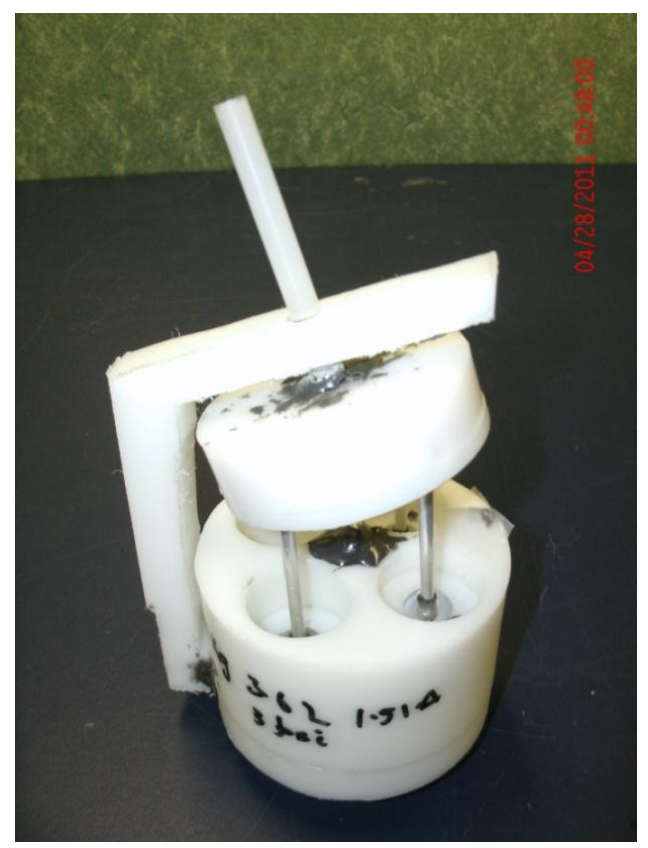

Figure 7b-Quad piston pump

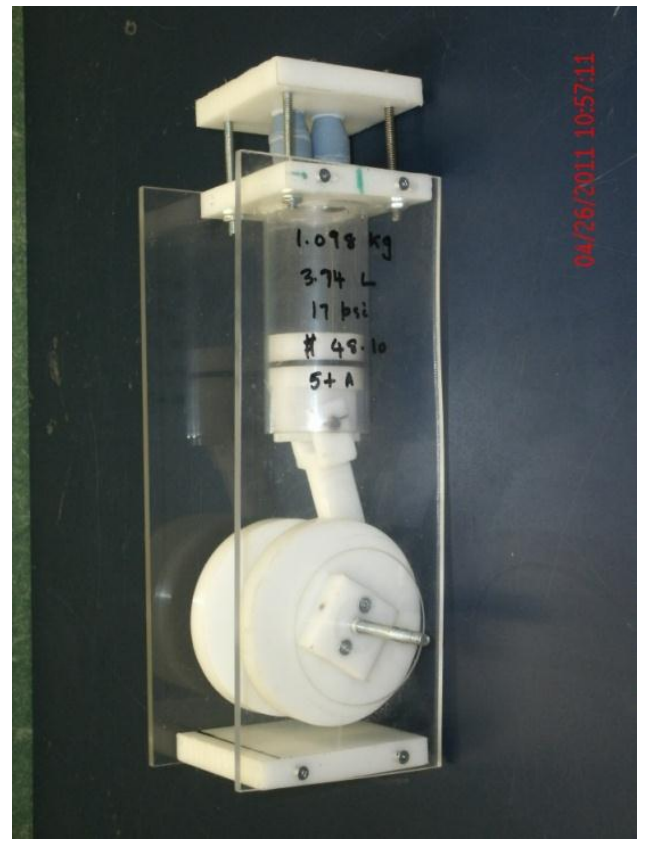

Figure 7c-Single acting piston pump

\section{References}

[1] James Leake, Jacob Borgerson, Engineering Design Graphics, John Wiley and Sons Inc., 111 River Street, Hoboken, NJ 07030-5774, 2008

[2] Shawna Lockhart and Cindy M. Johnson, Engineering Design Communication, Conveying Design Through Graphics, Prentice Hall, Upper Saddle River, NJ 07458, 2000

[3] Canadian Engineering Accreditation Board, Accreditation Criteria and Procedures

180 Elgin St., Suite 1100, Ottawa, ON K2P 2K3, For the year ending June 30, 2010,

Page 12, Sec 3.1.4 